\title{
Primitive Classification and Postmodernity: Towards a Sociological Notion of Fiction
}

\section{Karin Knorr Cetina}

\section{Introduction: Sociology beyond Modernism}

Postmodernist thinking in sociology is easily dismissed as gibberish taken over from French intellectuals and literary critics surveying the world from their Parisian desks or, worse still, from the vantage point of their brief travels to La Californie. It can be seen as an ephemeral fashion taken up by social theorists who are out of ideas, theorists who are finally getting bored with reinterpreting Weber, Durkheim and Marx. ${ }^{1}$ But it can also be seen as a movement sustained by developments within sociology which imply a rupture with Enlightenment thinking, a negation of many of the definitive features which have been associated with the modern. These developments nourish a break with modernist claims by offering empirical documentation for their findings, a feature not entirely irrelevant to a science that wants to make assertions about the social world. In addition, they suggest that postmodernity is something more than a chapter in the sociology of intellectuals and their malaise with the world, as Bauman suggests (1988), or a trend in aestheticism keyed to increased individualism, multiple choices, and 'self-enrichment' or 'self-enlargement' (Rorty, 1986). The perspectives which push sociology from within beyond the grand master themes of modernist thinking and modernist research, differentiation and rationalization, and which lead, as one might say, to pastmodern thinking, are microanalysis and constructionism. Microanalysis is the detailed description of social episodes through means such as ethnography, discourse analysis or visual methods. It has flourished in ethnomethodology, symbolic interactionism, social phenomenology, and so on, and has documented in detail the existence of life-worlds which theorists such as Habermas (1983) think we have lost, and the relevance of the body,

Theory, Culture \& Society (SAGE, London, Thousand Oaks and New Delhi), Vol. 11 (1994), 1-22 
of interpretative flexibility and reflexivity which interest postmodernists. Most importantly, microanalyses have discovered, emphasized and described the local nature of modern life; the whole body of microanalytic research rests on localizing concepts, epitomized by terms such as 'local order' and 'indexicality' in ethnomethodology, 'situation', 'setting' and the 'stage' metaphor in symbolic interactionism, 'province' of meaning and 'situatedness' in phenomenology, etc. The whole microanalytic revolution is a revolution not about what is small, but about the spatialization of experience. Microanalysis has turned away from conceiving the world in terms of individuals and actors, to conceiving of it in terms of sequential environments. Hence the replacement of notions such as 'actor' by 'participant' and 'member', and hence the ease with which microanalytic perspectives have opened up, by looking at new spaces, invisible aspects of modern society, those which are hidden from modernity's official, developmental dimensions.

The local nature of much modern life contrasts sharply with totalizing ideas about economic development, reason and universal knowledge which are characteristic of modernity. Yet microanalysis alone is not enough. The break with modernism implies not just an extension of the Chicago School of methodology, however radicalized by an emphasis on local multiplicity. It implies not a new methodology but a new epistemology, a new conception of the relation of the knower to the known. Recent work in the area is marked by a deep questioning of the nature of reality, of our conception of knowledge, cognition, perception and observation. The approaches within sociology which have occupied this terrain are not just microsociological, they are constructionist. Constructionism is a doctrine most suited to penetrate into the internal environment of domains that appear unitary and homogeneous into the constitution of the factual, the real, the authoritative meaning. Constructionism holds reality not to be given but constructed; it sees the aggregate as composite, the uniform as heterogeneous, the smooth and even-surfaced as covering an internal structure. It has found texture where other approaches have found the simplicity of a single attribute, and discontinuity where others have found continuity and interpenetration. Moreover, some constructionist perspectives have added to the localizing concepts of microanalysis through introducing broader notions of 'environment' more keyed to perspectives on modern institutions than the microconcept of a situation. 
There are at least three brands of constructionism in sociology today which have their strongholds in different areas, in addition to the deconstructionism familiar to postmodernists. First and bestknown to sociologists is the social constructivism which takes its lead from symbolic interactionism, negotianism and Berger and Luckmann's text, The Social Construction of Reality (1967). It tends to document the social origin of seemingly 'objective' social events and structures through pointing out the interactional work accomplished by participants in bringing these events about, and the meanings and definitions continuously infused in the respective outcomes and situations. The main criticism has been that it remains unreflective towards its own construction and the use of social factors as tools in constructive work.

There is, second, the empirical, knowledge-oriented constructionism developed in the last ten years in the sociology of scientific knowledge. ${ }^{2}$ It is based on the assumption that the things which we consider the most real in our society are also the most scientific, hence to study the construction of reality today means to study epistemic practice. It has relocated scientific realism into the empirical analysis of fact-production as opposed to the philosophical analysis of the logic of fact-justification. Consequently, the notion of a 'productive locale', which in science is called a laboratory, has replaced - as a theoretical notion - the concept of organization (see Knorr Cetina, 1992). This approach has also given rise to the notion of fiction which I shall outline below.

Third, there is the cognitive constructivism derived from the biology of cognition and perception. It appears to be embraced by system-theorists and sociologists who adopt the notion of selforganization. The central doctrine of cognitive constructivism is that living systems, including, on a societal level, systems of communication (Luhmann, 1984), are informationally closed toward their environment. They respond to the environment based on recursive self-organization and internal reconstruction, but they cannot be directly influenced by it. The localizing concept introduced by this approach is the notion of a system, understood afresh in terms of its closure toward the environment and in terms of self-organization.

Constructionism has emphasized and empirically documented contingency and negotiation, rupture and discontinuity, and heterogeneity and fragmentation in social events. In this sense constructionist studies are continuous with the deconstructionism 
closely associated with postmodernists, but there are differences. The most conspicuous feature of deconstructionism is its focus upon language, literary discourse, signification and the meaning of texts. 'There is nothing outside of the text', as Derrida remarks (1976: 158). Constructionisms, on the other hand, encompass a much wider notion of practice which includes not only nontextual, but also non-verbal, and even non-human agency. ${ }^{3}$ Secondly, for deconstructionists, the important thing about meaning is that it is impossible to recover it unambiguously from a text or discourse. Indeed for deconstructionists, ${ }^{4}$ the very impossibility of unambiguous meanings may become the only 'meaning' literally recoverable. ${ }^{5}$ Constructionists, on the other hand, have maintained an interest in the social mechanics and social physics of heterogeneity and contingency. They dissolve our belief in the monolithic and awe-inspiring, but they do this not by showing how the monolithic is empty, but by showing us how it is built.

Nonetheless, constructionist studies too have had their deconstructionist readings. Social constructivism can easily be equated with petty negotianism, and leads to complaints, much as deconstructionism does, against the 'powerlessness' of such enquiries. Cognitive constructionism is struggling to get its transfer of images which depict the closure of systems such as the brain accepted when it comes to arguing the closure of social systems: unlike the brain, social systems have no obvious, unsurpassable informational or communicationial boundaries. Finally, constructionisms which imply a new theory of knowledge find themselves embroiled in struggles with realist and positivist beliefs (for example Sismondo, 1993), which see the results of these studies as a threat to scientific procedure and an expedient of arbitrariness and relativism in the social world. As Mary Douglas (1978: xv) remarks 'The ultimate explanation of the sacred is that this is how the universe is constituted'. Constructionism threatens our beliefs in this constitution, without promising a return, as modernist theories and critical theory have done, to a more truthful truth and a better nature.

\section{A Sociological Notion of Fiction}

However, constructionist studies, by the very questions they pose about nature, facticity and meaning, also open another possibility. They have something to offer to a strong notion of culture and practice that has become feasible in sociology in recent years along with the rise of postmodernist thought (cf. Featherstone, 1988a). 
What constructionist studies suggest is the pervasiveness and relevance of fictionality as a routine aspect of social life. Here we should acknowledge the excess meaning constructionist studies have unearthed in connection with their distrust in facts, objectivity and meaning. Yet we should recognize this excess meaning not as a threat to scientific procedure, or an expedient of the dissolution of all order into contingency, but as a routine feature of the social world. Suppose we stand, so to speak, the constructionist message on its head and consider its negative findings as worthy of analysis. If science, and modern institutions in general, do not run on facts, this is no reason for despair and resignation - it is rather cause to investigate the ways in which these institutions, if they do not run on facts, run on fictions.

Modes of fiction are ways of enchantment of the world, they are instruments of cultural imagination. When we talk about cultural imagination, we raise an issue about the key process of modernity and of modern institutions. The most prominent theoretical perspectives have linked these processes not to a gain of meaning but to a loss of meaning, they have seen them as major transformative trends toward greater commodification, rationalization, technicization. Weber, best known of all, held the trend responsible for the 'diminution of freedom' and the general 'disenchantment' of the world that grows out of the expansion of instrumental action (1905). Other transcriptions of the theme cast modernity as a process of alienation (Marx), as a loss of personal and interactional culture (Bourdieu, 1977; Luhmann, 1984) or as a loss of 'substance', the life-world and cultural traditions (Habermas, 1983). These 'losses' are replaced by a gain in abstract, formal and technical systems, a gain in legal principles, abstract values and expert/scientific procedure. ${ }^{6}$

Some of this clearly strikes a chord. The loss of 'substance' now includes the environment; to quote one analyst, a river today is not a river, it only looks like a river. ${ }^{7}$ Yet our new rivers may contain as much plant and animal (microbial) matter as their unpolluted precedents - matter which, however, we consider as unwanted, as 'out of category' as Mary Douglas might say, ${ }^{8}$ with our historical conception of rivers. Similarly, the fact that some regions of the world have experienced a loss of religious fervour ${ }^{9}$ does not signify that there exist no other mythologies to take the place of religion; it only means that the new forms may be out of category with, for example, the mode of integration that we posthumously attribute 
to previous traditions. ${ }^{10}$ The thesis of the disenchantment of the world fails in several ways. First, it rests on the equation of the content of particular belief systems or modes of operation - which have changed - with 'substance', 'meaning', the 'life-world', etc. in general. If the proposition of the 'loss of meaning' in modern and postmodern life is stripped of this equation, it amounts to a historically plausible but trivial assertion about the changing nature of meaning structures. Second, the assumption of the increase in formal, technical and abstract systems ignores the phenomenon that these systems are never abstract when they are enacted. Presumably, the meaning of abstract elements lies not in their formal definition but in their use. Third, the thesis fails in that it has not been systematically documented empirically. In fact, assessments like that of a trend toward the elimination of the life-world are ironic in face of the aforementioned microsociological studies in the last thirty years which demonstrate the procedures and forms of organization of this life-world.

From the micro-perspectives which document the life-world of modern institutions, it is clear that everyday practice still runs counter to the perceived disenchantment of the world. They testify to the presence of 'meaning' and 'tradition', of the 'body', of 'intimacy', 'local knowledge' and everything else that is often thought to have been bred out of 'abstract' and 'rationalized' systems. But is this assessment enough? I think not. I am not arguing for an upgrade or, better, recognition of symbolic and interpretative approaches - which exist after all - but for a specific notion which is keyed to the development of modern institutions, and which can catch up some of the features which have been noticed by constructionist perspectives. ${ }^{11}$ In a sense we can still work with a notion of enchantment, but it has to be more specific and precise than the general terms 'meaning', 'text' or 'interpretation' which flood the literature. It also has to be more specific and precise than the view stimulated by anthropology of cultural forms as symbolic forms.

\section{What Are Fictions?}

I have proposed that we stand the constructionist message on its head and learn from it the relevance of fictions. Fictions are enchantments of the world, but they are not only enchantments. Can we link a notion of modern institutions to the analysis of a stronger notion of operative fictions? What are operative fictions? 
Those sustained by the development of modern institutions, entangled in their practices, those which come into play when these institutions fulfill their goals and engage in instrumental action. Such fictions are imaginative works, but they are not quite the pleasurable art forms Clifford Geertz has in mind when he compares the Balinese cockfight with a performance of King Lear. A cockfight or a performance of King Lear is a cultural figure that catches up themes close to the heart of a society and some of its subcategories of members ${ }^{12}$ - themes like death, masculinity, rage, pride, loss or chance (1973: 443). It displays these categories, provides, to the natives, a metaphor of themselves, but it has no other reality nor function - the cockfight, as Geertz says, is 'really real' only to the cocks - it kills them. Although some forms of fiction in modern institutions are like that others are not. What interests me is a wider notion of fiction as registers and symbolic technologies embedded in or constitutive of the performance of modern institutions.

In everyday usage fictions are, roughly, objects which are not literally true, which are not the real thing, which are possibly shams or simulations. Etymologically, fictions derive from fingere: the act of fashioning and shaping which includes imitating and inventing. Etymologically, fictions carry only a weak factor-loading on the truth-falsity dimension and a stronger one on the dimension of shaping and forming. Yet the notion of fiction I want to propose draws more on a different aspect of the concept. Fictionality arises from the transformations of forms of symbolic organization in modern institutions and the cultural attributions of reality, literality or normality which apply to these forms. It rests on a difference between a discourse and a counterdiscourse, between behavioral and other behavioral or symbolic repertoires, between different definitional frames sustained by participants or practices. It is a phenomenon of two or more registers or regimes which may alter the dimension of phenomena, bring them into a different medium, take them out of one kind of social space-time and install them into another. Fictionality refers to the transposition of things into an alternate reality in which work is carried on, without the original register being eliminated. It is a codeword for the phenomenon that (institutional) reality (today?) comes in alternates which play upon each other, edge against each other, contradict each other or exhibit some other kind of relationship that rests on their difference. ${ }^{13}$ The transposition from an experiential into a semiotic 
and representational regime can institute such alterations - with changes of the perspective, the resources, the technology brought to bear included; but so can reclassifications, or what I shall call social simulations (see below). Fictionality refers to the inflationary introduction of layers of organization and order which increase the viscosity and texture of modern institutions.

Modern institutions, I want to claim, continually produce fictions, steer their way through fictions, work with fictions and become founded upon fictions. Consider first the older example of English and Roman law, in which a variety of legal fictions apply which serve different functions in legal applications. ${ }^{14}$ Some of these fictions are condensed versions of legal rules, as the fiction in English law that husband and wife are one person, or the equivalent in Roman law, which says that the wife is the daughter of the husband. Other fictions appear to be links to a competing moral order, like the legal fiction that everybody knows the law. Older authors saw these fictions as 'marvelous' means for connecting legal rules with reason and justice: for example, the fiction that everyone knows the law brings the rule that lack of knowledge is no excuse for an offense in accordance with the moral value that it is unfair to punish someone for an offense against a law he or she does not know. Even the idea of adoption was originally introduced into law as a legal fiction: the fiction that family bonds can be created artificially. The law uses fictions as instrumental constructs which serve to bridge gaps in the body of legal rules or between law and justice.

But the law and its use of fiction to hide, sustain or complement the principles according to which it operates, is one case. These are instrumental fictions, distinguished as such by participants and introduced to serve a specific purpose or solve specific problems. What interests me more is the kind of fictionality whose existence and meaning is less obvious and about which we can learn, paradoxically, from the most highly technicized domains, those on which the greatest accent of reality and rationality is conferred by participants and observers. Fictions are central to how these institutions conduct their business; yet they are not central in the same manner. There are types of fictional forms which need to be distinguished. I shall draw attention to three types: symbolic ('primitive') classifications, social simulations and fictionally operating systems of knowing. I shall expound symbolic classifications in some detail but be brief about the other categories which 
cannot be adequately explained within the confines of the present paper. ${ }^{15}$

\section{Primitive Classifications}

The first class of fictions are symbolic (re)classifications of categories in terms of metaphors and analogies from the natural and social order. In contrast to instrumental fictions which often comprise isolated principles, what we are dealing with here are often whole systems of symbolic categories which display a certain coherence and elaboration. Such systems of classification have interested social scientists at least since Durkheim and Mauss wrote their famous essay on Primitive Classifications (1963). Yet until today, primitive classifications have no satisfactory interpretation.

For Durkheim and Mauss, primitive classifications were social projections. They looked at symbolic classifications of natural objects by native tribes, such as the division of all things in nature as belonging to one or the other 'totemic' animal. Durkheim and Mauss wanted to prove the social origin of these classifications. They did not believe that the human mind had the innate capacity to classify the things surrounding it spontaneously and by sort of natural necessity (1963: 7). Instead, they thought the mind needed a model, and this model was society: if the society was divided up in a certain way, then the rest of the universe would be divided up analogously and related to the categories established by social organization. 'The classification of things reproduces the classification of men.' This was Durkheim and Mauss's well-known thesis, whose singular value it is, as Needham (1963) pointed out, to direct the attention of sociology to the topic of classification.

The thesis itself proved untenable, but the question of category derivation remained and has stimulated further thought. Today the more interesting cases of primitive classifications are not those which are religious, but those we find in modern highly technicized and rationalized institutions. Why are fictional categories employed in modern institutions although technical vocabularies and literal descriptions usually exist to circumscribe the phenomena of interest? The most prominent answer comes from a modern Durkheimian, Mary Douglas (1987). Institutions, she argues, are conventions, and conventions need some stabilizing principle which points away from the fact that they are socially contrived arrangements. This stabilizing principle is naturalization, the links an institution establishes with 'natural categories' through metaphor 
and analogy. The convention of the sexual division of labour, for example, may be justified in terms of an analogy with the complementarity of the right and the left hand, and the analogical relation of head to hand can be used to justify such diverse social arrangements as the class structure, the inequality of the education system and the division of labour between manual and intellectual work.

Science, a paradigmatic modern institution, also enlivens its universe through symbolic classifications. Consider the jewel in the crown of basic disciplines, experimental high energy physics (see Knorr Cetina, 1995: Ch. 5). Like in any other science, the definition of things is accomplished by technical vocabularies. A huge measurement instrument such as a detector and, presumably, all of its thousands of parts can be classified or paraphrased in a technical language. Moreover, physicists seem to share enough of this vocabulary to make themselves understood and to communicate with each other within this technical language. Yet there exist, in addition to the technical language, imaginative terminological repertoires which reclassify technical objects and distinctions. These constitute a symbolic universe superimposed upon the technical universe; a repertoire of fictional categories and distinctions from the everyday world which are extended into science where they reformulate, elaborate and at times fill in for technical categories and distinctions.

Consider an example. Some areas of physics, especially experimental high energy physics, are known for their massive requirement of technology - of three-storey-high detector complexes seven storeys underground, of 30 miles-in-diameter beam pipes and magnets, of tens of thousands of yards of cables and wires, of rooms full of electronic crates, and so on. Advances in high energy physics are often presented in terms of energy regimes, and energy regimes are regimes of machines: of colliders and accelerators which provide higher and higher energies, of detectors which can deal with ever higher luminosities, and of computers which are fast enough to handle huge amounts of information within fractions of a second. It is this technology which consumes the massive flow of money high energy physics requires, and which necessitates, by its sheer size and complexity, the formation of large and long-lasting international collaborations. Seen from this perspective, these areas of physics are indubitably brandmarked by, driven by and dominated by machines. Yet seen from within the vocabularies in terms of which the physicists frequently address these technical devices, these are 


\section{FIGURE 1}

Some Physiological Conditions and Behavioral Idiosyncrasies of a Detector

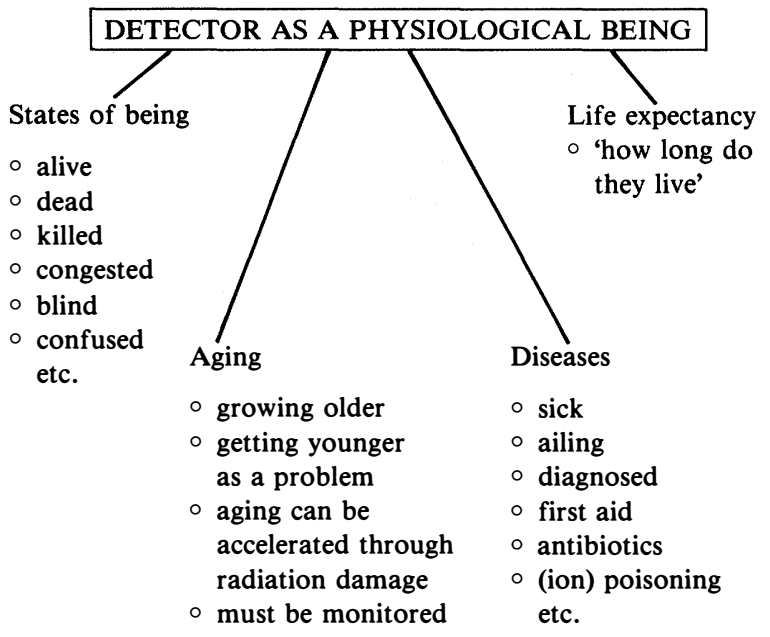

\section{BEHAVIORAL IDIOSYNCRASIES}

$\circ$ each detector is different from others

- background depends on specifics

- smearing depends on specifics

- responsible for 'meaninglessness' of data which are not corrected

$\circ$ difficult to simulate

less machines than biological organisms with a life and a life-time of their own. One example is the 'aging' of a detector. Why involve a biological process such as aging in a technical event? Moreover, 'aging' is just one term in a much larger system of categories which fit to each other, supplement each other, and in which two features stand out: the terms are physiological and refer to the qualities of an organism, and they suggest an autonomous being which, in the aggregate, can also be a social being.

There is no need, in this paper, to go into the details of this taxonomy which is expounded elsewhere (see Knorr Cetina 1995: Ch. 5). Suffice it to say that in addition to the behavioral states and idiosyncrasies (detectors are true individuals!) given in Figure 1, this vocabulary encompasses behavioral capabilities which imply, 
on the side of the instrument, a perceptual apparatus (the instrument 'sees'), behavioral responsiveness, achievement levels ('dopability'), susceptibility to the treatment of diseases, communication capacities and behavioral limitations. The question one needs to address is how we interpret such classifications. For Mary Douglas, the message would be clear. A machine is itself a convention and an artifact. The analogy from biology and physiology confers natural status on the crystallized social relations represented in the machine. The analogy builds strength for a physical instrument that does not in itself have legitimacy, consumes huge amounts of money and manpower, and would be, without the analogy from life, an a-moral, a-social, non-natural being.

On the other hand, is it really plausible that the spark of legitimacy is conferred so easily to things in modern institutions? In physics anyway, substantial organizational work goes into purchasing legitimation. There are special units at the big laboratories whose task it is to cultivate and promote the cause of high energy physics, and these units continually produce a stream of linguistic events which display and celebrate the achievements and relevance of these organizations' work. The function of the general director of a large laboratory is to a significant degree to pursue, with government agencies, ministers of science and prime ministers ('Mitterand at CERN', as the headlines read), questions of the relevance, usefulness and need for a particular research and development. Building new detectors is justified in this context in terms of the harvest of new particles they bring, in terms of spin-off effects, industry development, the training of physicists potentially needed by this industry or by the military, and in terms of international competitiveness and international relations. There is indeed a discourse of legitimation, but this does not include analogies such as the above. Nor are these analogies made public such that they could provide legitimation. More generally in our societies, conventions such as organizational structures are often justified in terms of efficiency, or they are, like conventions within the education system, grounded in law, and the legal provisions are justified with respect to democratic principles such as equality of opportunity and freedom of choice.

In view of the complex machineries modern societies install for purposes of image building and legitimation, the belief that the above classifications do this work is not plausible. It ignores the realities of economic action and political calculation in industrial 
societies. But what if we broaden the thesis to make it more compatible with a Goffmanian view of the symbolic as a dramatic construction, perhaps, as Geertz (1973: 445) suggests, a dramatic construction participants place upon the grand themes everyone is confronting in daily life ? $^{16}$ Are not the themes of life, death, illness/disease, of aging, physiologies, etc. encoded in machine classifications also the topics we experience in dealing with ourselves, but put into dramatic shape? The answer is yes, yet the interpretation is unsatisfactory. Why the need to identify routine features of a machine with these topics? What do we do with the quite different classifications of other aspects of participants' work, how do we explain which symbolic repertoire is chosen for which area? Is it possible to construct symbolic classifications and not catch up the common themes of our everyday experience?

I believe there is, for the fictional classifications of the above kind, a better interpretation. These classifications owe their divisions much more to their capacity to model the concrete interactions of the members of an institution than to participants' disinterested curiosity about the working of individual lives or about the workings of nature. They codify something that lies at the heart of the working of these environments. They codify who, within the walls of the institution and independent of external definitions, is an organism and who is a machine, who are agents with powers and dispositions to react, who is alive and who is not, who is a human and who is a non-human being. In other words, they catch up the ontologies instituted in local settings and the social relations which flow from these ontologies, and which include relations to nonhuman participants. The ontologies are specific to the type of locale; they are reconfigurations of, to borrow a term by Merleau-Ponty (1962), ${ }^{17}$ self-other-things, of the relations of subjects to objects in the external environment, or of the relation between the natural and the social order. For the 'natural' order established in these institutional settings a detector is not (just) a mechanical device, nor a 'dead' machine, nor even a sophisticated information technology (an outsider's definition) but a physiological being with needs and requirements like other physiological beings. It must be treated like one and interacted with like one. The epistemic procedures participants use with respect to this object differ markedly from the epistemic procedures used in fields like molecular biology in which real organisms (mice, microbes) are reconfigured as machines (see Knorr Cetina, 1995: Ch. 6). 


\section{Social Simulations}

Primitive classifications, then, codify the situated embodied production of relevant ontologies, but institutions do not only run on ontologies. They also need to organize their own survival over time. There is a second class of fictions which I see in relation to an institution's construction of its own life course and which one could call, to choose a term proposed by Baudrillard (1983), ${ }^{18}$ social simulations. Simulations are processes an institution sets up which aim at something that is real, but which are, through native or non-native observers, also contradicted by second and third voices. Formal organizational structures often have the character of social simulations. Consider four organizational structures implemented in four parallel huge international collaborations designed to create, in the same area of science, a new piece of technology and knowledge ${ }^{19}$ One features a sort of parliamentary democracy, complete with a written constitution, strict voting rules, exact indications of who is allowed to vote or run for which office and occupy it for how long, and so on. The second is based upon informal, interactional self-organization. The third is called 'teutonic', which means it has strong leadership and an old boys' network which runs things. And the fourth uses the device of, in participants' jargon, 'splitting the collaboration down the middle' into two competing camps which report to a leader but do not talk to each other. The four collaborations are stunningly different in describable, accountable and constantly reported and talked about terms: they enact four different models, in a rather conspicuous way. What is interesting is that these models of organization which are enacted and displayed apparently have little effect on the performance of the collaborations - the achievements are very similar. ${ }^{20}$ Moreover, as in all organizations, there are native counter-voices, redescriptions of the 'real' organization not quite in agreement with the models.

In other words, in terms of their effectiveness - but also in terms of their actual realization - these models appear to be fictions in the sense of simulations. What, then, do these forms of organization do? Why the discourse about them, the stunning display of their features? The discourse, the organization, is the fluid analog of the functioning of symbolic classifications: it works like a code - a set of symbols for the 'style' and the 'quality' of a collaboration. This 'style' and the 'quality' has strong implications for how a collaboration sustains itself over time, and for how it spawns and 
seeds new collaborations. To form a collaboration, one must attract physics institutes willing to participate, convey organizational effectiveness at the same time as respect for participants, and stimulate confidence in the collaboration among those who decide whether it will be allowed to conduct an experiment or not. Collaborations have no future if they disqualify themselves on the level of their habitus and style. Again, fictionality points to the situated reproduction of a new level of order, a new level of organizations - it points to the genealogical reproduction of the superorganisms which are called collaborations within a new time frame. Fictionality captures the shift from an organizational register to a genealogical regime of collective survival and arrangement across time - and the back and forth between these frameworks witnessable in everyday practice and discourse.

\section{Fictionally Operating Systems}

The last illustration of a type of fictionality in modern institutions refers to closed systems analogous to those which interest cognitive constructionists (see above). Closed systems are systems which operate entirely within their own medium and machineries of world construction. An example is the brain, which the biology of cognition sees as informationally closed towards its environment. Perception, for example, is accomplished by the brain, not the eye, and the brain can only construe what it sees from signals of light intensity which arrive at the retina. In order to form a picture of the nature of the source of these signals, the brain makes reference to its own previous knowledge and uses its own electro-chemical reactions. Phrased differently, in perception the brain only interacts with itself and not with an external environment. The brain reconstructs the external world in terms of internal states, and in order to accomplish this the brain 'observes' itself (Maturana and Varela, 1980).

To return to a high tech, high rationality knowledge enterprise such as modern physics, I would like to maintain that it, too, operates as a closed system. Closed systems cannot build, with the environment of interest to them, a shared life-world. They lack the possibility of co-presence postulated by Schütz (e.g. 1970) as an important feature of face-to-face situations. They equally lack co-temporality, the possibility of conjoint time, and the possibility of conjoint status of human agents with the status of nonhuman entities or objects. High energy physics deals with the total absence 
of communality between human agents and objects through transferring this communality on the technology it uses (it enjoys co-presence with the objects studied), and through placing its bets heavily on signs of the objects. The objects themselves, subatomic particles, are as participants say, 'phantasmatic' - they are too small, too fast and too dangerous collectively to ever be handled directly. Moreover, they are always history, always already transformed into other entities. The ontology of these objects is an ontology of the past, the absent, the decayed and transfigured. Through myriads of internal operations, representations of these objects in an instrument that catches the signs of these objects are transformed into representations of the catching instrument, and these into representations of physics. But the layers of representation between internal operations and the environment are but one aspect of these systems. Another is that the signs which are so heavily sought after and transformed into other signs are themselves highly fictitious, they are mostly shams and fake signs - the real signs of interest must be extracted from a sea of deception. A third feature of the system is the fictionality of measurement. Because of the hypercomplex and idiosyncratic sign catching measurement apparatus, measurements are said to be meaningless in themselves. Hence even quantitative measurements must be seen as fictions which have to be supported through re-creations of the apparatus and through predictions of physics theory. Measurements walk, as one might say, always on such crutches. They are not the standalone arbiters of progress and theoretical predictions which they are, supposedly, in other fields. ${ }^{21}$

Systems such as the above are driven by a certain relation between epistemic subject and object that puts into question received models of knowing. The interesting question is of course how closed systems nonetheless derive truth effects from their fictional operations. The answer is that they install a new epistemic regime; they shift their operations from observing the world to observing and understanding themselves, and from gaining positive knowledge to gaining knowledge of the errors and limits of knowing. ${ }^{22}$

\section{Summary and Conclusion}

The phenomenon of the semiotic and fictional constitution of highly technicized, highly rationalized institutions which, like physics, trade in reality, carries a message for our assessment of modernity. If modernity has led to an increasing loss of magic and 
enchantment, it has not led to a loss of fictions, nor to a loss of virtuosity in operating with symbolic technologies of order and organization. This has been illustrated by reference to primitive classifications, to what I called social simulations and to systems of knowing which operate closed off from an environment which they observe.

Two things should be noted about the forms of fictionality I have discussed. First, I am not suggesting that the notion of fiction be used for all processes in evidence in modern institutions. The closed system description, for example, fits a science that is most extreme in the degree to which it points beyond received mechanisms of operation - one that sums up modernity and thrusts it forward it does not fit, among other cases, molecular biology, for which an open system conception is more adequate. In other words, I have introduced the notion of fiction not as a marker in an epistemic narrative about the general status of knowledge, but as an analytic concept suitable to describe - and theorize - concrete modern institutions. Second, it is important to realize that in all cases considered, fictions are not idle rhetoric, not symbols reduced to essentially decorative use. Instead, what is apparent is a gain of behavioral and symbolic repertoires that adds to the viscosity of modern institutions and that fuels and represents new levels of locally reproduced order. Fictionalities of the above kind lift modern institutions out of the purely technical, but also out of the purely social, and transform them into cultural systems of multiple order. On the second level, they install new arrangements which represent, for participants, coherent and viable frameworks of activities - new epistemic regimes of self-observation and selfunderstanding in an institution that deals with the real, new ontologies resulting from reconfigurations of self-other-things, and new temporal orders of reproduction that deal with the rebirth and continuity of flexible entities such as collaborations - entities which are not legally stabilized and can draw on no other source of existence than their own attractiveness and entrenchment. Fictions institute and suggest a play upon orders, a progress from one arrangement and from one disciplinary framework to another. They demonstrate not a horizontal but a hierarchical multiplicity of patterns which are themselves not of the same order (not all social) on which the functioning of these institutions depends - it is the new order which makes the institutions I considered work.

The phenomenon that highly technicized systems, if you strip 
them of their massive instrumentality, display themselves as systems operating with and by means of fictions, can lead to a notion of the re-enchantment of the world which takes its lead not from the status of religious traditions and belief systems but from the practices of participants in local environments. For Durkheim and Mauss, as Douglas emphasized (1987: 97), the sacred was nothing more mysterious than shared, deeply cherished classifications. For us, they need not be anything more mysterious than manifoldly present and deeply entrenched operative fictions. Such fictions document a continuity with baroque, perhaps archaic codings of the life-world, but they also document a continuity with the technical, formal, and instrumental (was the sacred always hybrid?). The sacred, in the form of operative fictions deeply entrenched and embedded in the technical and instrumental, seems to be present today more than ever before, and more than ever in need of being introduced into social theory and the investigation of modern institutions.

\section{Notes}

1. See also Mike Featherstone's Introduction to the Theory, Culture \& Society volume on 'Postmodernism' (1988b: 195-216). Featherstone surveys some of these complaints and reviews several meanings of postmodernism in various fields.

2. For the original works which launched the constructionist tradition in the study of science see Knorr (1977), Latour and Woolgar (1979, republished 1986), and Knorr Cetina (1981, pbk. 1985). The approach has been so accepted that most works in the new sociology of science and technology today can be labelled (or label themselves) constructionist, with the question being not whether constructionism is justified but what kind of constructionism one advocates. For a review of different versions of constructionism in science studies and the arguments related to this see Sismondo (1993). Note that the recent sociology of scientific knowledge promoted by Bloor (1976), Barnes (1977) and Collins (1981), while being a relativist perspective, needs to be distinguished from the above constructionist approach.

3. But see the problems associated with the attempt to include non-human agency in the analysis as pointed out by Collins and Yearley (1992).

4. This does not hold for Foucault, who also pointed out the unrecoverability of definitive meaning (e.g. 1972).

5. See for example Paulson (1988: 93ff). Reading texts, for deconstructionists, leads not to the extraction of univocal meanings but to what the literary critic Miller calls an 'impasse' or 'mise en abyme' (1976: 11), a 'treacherous abyss of doubled and redoubled meanings' (1976: 7). He adds that there is no strategy by which a critic can " "reduce" the language of the work to clear and distinct ideas' (1976: 324).

6. Husserl, for example, associated rationalization with the rise of the scientific method which, according to him, 'abstracts' from all cultural and spiritual aspects of human practice (1976). And only recently Habermas, in refashioning 
Weber, Husserl and other theorists, linked rationalization to what he calls the 'colonialization' of the life-world by technical systems or, in alternative language, to the residualization and marginalization of everyday taken-for-granted knowledge, personal forms of communication and everything else that can be associated with 'substance' and 'substantive experience' rather than formal procedure (1983). For a theorist who seeks to retain some modernist assessments of the world while incorporating elements of micro-approaches see Giddens (e.g. 1990).

7. Unfortunately, I am unable to recover the author of this quote.

8. See her book Purity and Danger (1966) in which she considers 'dirt' as nothing more than matter out of place.

9. Clearly this assessment holds only for certain areas of the Western world. It is not even correct, in this crude form anyway, for the United States, which has one of the highest percentages of 'believers' ( 95 percent say they believe in God) and church members (more than 60 percent belong to a religious denomination, see the Yearbook of American and Canadian Churches, 1980).

10. Within sociology, the 'new institutionalism' (e.g. Meyer and Rowan, 1977; Powell and DiMaggio, 1991) has pointed out the symbolic dimension of 'formal' structures and thing-like entities such as organizations. The analyses conducted within science studies in the last ten years support many claims of the new institutionalism, yet go in a somewhat different direction (see the notion of fiction below).

11. To repeat, the problem with sociology's relation to the symbolic is not that the discipline simply ignores the phenomenon; it is rather that the phenomenon is either translated into something as common and untelling as 'language' or 'communication', or that it is separated out as the domain of perspectives such as interpretative approaches which are seen as having not much to say to the movement and development of modern societies.

12. More to the heart of male members of these societies it would seem.

13. What cannot be ignored is what happens between the forms installed. For an observer, this means that he or she must not side with one version or smooth out discrepancies, but rather consider the discrepancies as part of the analytic message.

14. For a brief historical summary of legal fictions, see the respective entry in the Encyclopaedia Britannica.

15. The research from which my claims are derived is based on six years of participant observation at the European Center for Particle Physics, the CERN in Geneva. Comparative results were obtained for molecular biology at a Max Planck Institute in Germany. The research is a study of epistemic cultures and of the social forms and theories embedded in the most 'modern' of modern institutions, science (Knorr Cetina, 1995). The results for molecular biology are partly reported in the above volume. Full documentation of this study can be found in Amann (1990).

16. Neither Geertz nor Goffman might agree with the view I attribute to them. I am not referring to what these authors might actually offer as an explanation for primitive classifications in modern institutions if they were asked, but to possible interpretations derived from the approaches for which they stand. As to the Goffmanian view, see for example Goffman (1959).

17. Merleau-Ponty's original notion in the French version of his book is 'le système "Moi-Autrui-les choses"' (1945: 69). For the English translation and the exposition of this concept see Merleau-Ponty (1962: Ch. 5 and p. 57). 
18. For a detailed explication of Baudrillard's notion of 'simulation' see Kellner (1989: Ch. 3).

19. Again, I must ask the reader to consult the detailed description of these cases for further information (Knorr Cetina, 1995: Chs 7 and 8).

20. It is, of course, not easy to judge whether there is any real effect. One piece of supporting evidence is that the two collider experiments preceding the ones mentioned were also organized in contrary ways, yet were both successful in 'discovering' the $\mathrm{W}$ and $\mathrm{Z}$ zero particles for which they searched within days of each other. The more important point is perhaps that organizational structures tend to be simulations in the sense of being contradicted by participants in these forms.

21. They become, as one might say, real only through the unreal.

22. This, too, like all empirical claims in this paper, would have to be substantiated in more detail. I ask the reader's trust that this substantiation is delivered elsewhere in much detail (Knorr Cetina 1995: Ch. 3), and that the theoretical points made here have their roots in long and careful research.

\section{References}

Amann, K. (1990) 'Natürliche Expertise und Künstliche intelligenz: eine mikrosoziologische Untersuchung von Naturwissenschaftlern', PhD thesis, University of Bielefeld.

Barnes, B. (1977) Interests and the Growth of Knowledge. London: Routledge \& Kegan Paul.

Bauman, Z. (1988) 'Is There a Postmodern Sociology?', Theory, Culture \& Society 5(2-3): 217-37.

Baudrillard, J. (1983) Simulations. New York: Semiotext(e).

Berger, P. and T. Luckmann (1967) The Social Construction of Reality. London: Allen Lane.

Bloor, D. (1976) Knowledge and Social Imagery. London: Routledge \& Kegan Paul. Bourdieu, P. (1977) Outline of a Theory of Practice. Cambridge: Cambridge University Press.

Collins, H.M. (1981) Knowledge and Controversy: Studies in Modern Natural Science, Special Issue of Social Studies of Science 11.

Collins, H.M. (1992) 'Epistemological Chicken', pp. 301-26 in A. Pickering (ed.), Science as Practice and Culture. Chicago, IL: University of Chicago Press.

Derrida, J. (1976) Of Grammatology, trans. G.C. Spivak. Baltimore: Johns Hopkins University Press.

Douglas, M. (1966) Purity and Danger: An Analysis of Concepts of Pollution and Taboo. London: Routledge \& Kegan Paul.

Douglas, M. (1978) Implicit Meanings: Essays in Anthropology. London: Routledge \& Kegan Paul.

Douglas, M. (1987) How Institutions Think. London: Routledge \& Kegan Paul.

Durkheim, E. and M. Mauss (1963) Primitive Classifications. Chicago: The University of Chicago Press.

Featherstone, M. (1988a) 'Towards a Sociology of Postmodern Culture', in H. Haferkamp (ed.), Culture and Social Structure. Berlin and New York: De Gruyter. 
Featherstone, M. (1988b) 'In Pursuit of the Postmodern: An Introduction', Theory, Culture \& Society 5(2-3): 195-215.

Foucault, M. (1972) The Archaeology of Knowledge, trans. A.M. Sheridan Smith. New York: Pantheon.

Geertz, C. (1973) The Interpretation of Cultures. New York: Basic Books.

Giddens, A. (1990) The Consequences of Modernity. Stanford: Stanford University Press.

Goffman, E. (1959) The Presentation of Self in Everyday Life. New York: Anchor.

Habermas, J. (1983) Theory of Communicative Action, 2 vols. Boston: Beacon.

Husserl, E. (1976) 'Die Krisis der Europäischen Wissenschaften und die transzendentale Phänomenologie', Husserliana Bd. IV, 2nd edn. The Hague: Nijhoff.

Kellner, D. (1989) Jean Baudrillard. From Marxism to Postmodernism and Beyond. Stanford: Stanford University Press.

Knorr, K. (1977) 'Producing and Reproducing Knowledge: Descriptive or Constructive?', Social Science Information 16: 669-96.

Knorr Cetina, K. (1981/1985) The Manufacture of Knowledge: An Essay on the Constructivist and Contextual Nature of Science. Oxford: Pergamon Press.

Knorr Cetina, K. (1992) 'The Couch, the Cathedral and the Laboratory. On the Relationship between Experiment and Laboratory in Science', pp. 113-38 in A. Pickering (ed.), Science as Practice and Culture. Chicago: University of Chicago Press.

Knorr Cetina, K. (1995) Epistemic Cultures: How Science Makes Sense. (Forthcoming).

Latour, B. and S. Woolgar (1979/1986) Laboratory Life: The Social Construction of Scientific Facts. Los Angeles: Sage. Republished 1986 by Princeton University Press.

Luhmann, N. (1984) Soziale Systeme. Grundriss einer allgemeinen Theorie. Frankfurt: Suhrkamp.

Maturana, U. and F. Varela (1980) Autopoesis and Cognition: The Realization of the Living. Dordrecht: Reidel.

Merleau-Ponty, M. (1945) Phenomenologie de la perception. Paris: Gallimard. English translation 1962, Phenomenology of Perception. London: Routledge \& Kegan Paul.

Meyer, J. and B. Rowan (1977) 'Institutionalized Organizations: Formal Structure as Myth and Ceremony', American Journal of Sociology 83: 340-63.

Miller, J.H. (1976) 'Steven's Rock and Criticism as Cure', Georgia Review 30: 5-31, 330-48.

Needham, R. (1963) 'Introduction', in E. Durkheim and M. Mauss, Primitive Classifications. Chicago: University of Chicago Press.

Paulson, W. (1988) The Noise of Culture: Literary Texts in a World of Information. Ithaca, NY: Cornell University Press.

Powell, W.W. and P.J. DiMaggio (eds) (1991) The New Institutionalism in Organizational Analysis. Chicago: University of Chicago Press.

Robertson, R. (1988) 'The Social Significance of Culture: Some General Considerations', Theory Culture \& Society 5(1): 3-23.

Rorty, R. (1986) 'Freud and Moral Reflection', in J.H. Smith and W. Kerrigan (eds), Pragmatism's Freud: The Moral Disposition of Psychoanalysis. Baltimore: Johns Hopkins University Press. 
Schütz, A. (1970) Collected Papers, vol. 3, Studies in Phenomenological Philosophy, I. Schütz (ed.). The Hague: Nijhoff.

Sismondo, S. (1993) 'Some Social Constructions', Social Studies of Science 23(3): 515-53.

Weber, M. (1905/1930) The Protestant Ethic and the Spirit of Capitalism. New York: Scribner.

Karin Knorr Cetina teaches at the Faculty of Sociology, University of Bielefeld, Germany. Her recent publications include 'The Microsocial Order', in N. Fielding (ed.), Actions and Structure (London, 1988); 'Laboratory Studies: The Cultural Approach to the Study of Science', in J.C. Petersen et al. (eds), Science, Technology and Society Handbook (Los Angeles, 1994); and Epistemic Cultures: How Science Makes Sense (forthcoming, 1995). 